\title{
De los espacios regionales que integran el país
}

\section{On regional spaces that comprise the country}

García Martínez, Bernardo (2008), Las Regiones de mÉXICO. Breviario geográfico e histórico, El Colegio de MéXico, MéXico, 351 PP., ISBN 968-12-1322- ${ }^{1}$

En su acepción convencional, una región es una porción de la superficie terrestre que se distingue por una o más características o atributos (naturales o resultado de la actividad humana) que permiten dar una medida de unidad y al mismo tiempo de diferenciación respecto de áreas contiguas. A partir de este criterio de diferenciación, una región puede ser cultural, económica, política, morfológica, natural o fisiográfica, lo cual hace posible identificar esa región ya sea por uno, múltiples o la totalidad de atributos. Y esto es lo que le confiere a la región su unicidad.

Pero una región también puede ser producto del sentimiento de un grupo asociado a un área geográfica, como puede ser la Sierra Tarahumara, la de los huicholes o El Lacandón. Por otra parte, puede ser el resultado de un esfuerzo del gobierno central por crear un orden intermedio entre éste y las unidades políticoadministrativas locales, con propósitos de gestión, planeación o programación.

Para Bernardo García, las regiones son un producto histórico enlazado con un medio físico (p. 12). Pero no es lo mismo -diceidentificarlas que delimitarlas. Así, un criterio para identificar una región puede ser el medio físico que permite distinguir diferentes aspectos de altitud y latitud que expresan rasgos orográficos y climáticos conformando un paisaje del medio físico; otro criterio es considerar la ocupación humana y las variables sociales, económicas o políticas que se asocian para formar un determinado paisaje cultural.

La delimitación de una región debe reflejar coincidencias y divergencias físicas y humanas, y son, dice el autor, "los movimientos e intercambios humanos a lo largo del tiempo [los que]

\footnotetext{
${ }^{1}$ Esta reseña se preparó para leerse en la presentación del libro en El Colegio Mexiquense, en Zinacantepec, Estado de México, el 14 de mayo de 2008.
} 
cuentan $[. .$.$] más que el medio físico [...] es el tejido social que$ se ha formado a lo largo de la historia” (p. 28). Se trata de algo que no está determinado por el medio físico o cualquier otro factor específico, sino que es expresión de un sistema funcional. Así, "una región [...] es un espacio funcional y dinámico que alberga relaciones, intercambios e identidades culturales integradas históricamente y cuya individualidad es percibida por quienes participan en ellas” (p. 29).

Debido a que las regiones son producto histórico, entonces es claro que el concepto de región es tan sencillo como complicado: "la región es al espacio -dice Bernardo García- lo que una época es al tiempo, es decir, una parte del conjunto, un pedazo del total". Con respecto al tiempo, "las épocas pueden delimitarse o dividirse y subdividirse de mil maneras diferentes, abarcando periodos históricos de muy poco tiempo, como por ejemplo el del gobierno de un presidente, o de muchos, como cuando se habla de la época prehispánica o la colonial. Algunos periodos -continúa el autor- pueden tener un principio y un final muy precisos mientras que otros solo se pueden delimitar vagamente. [...] Con las regiones ocurre prácticamente lo mismo. Pueden ser enormes o pequeñas [...] puede pretenderse que sean muy definidas en sus límites, como en las regiones administrativas [...] o dejar sus linderos en la ambigüedad como es el caso de las regiones calificadas como áridas o dinámicas” (p. 12).

No es el caso extenderme en el concepto de región ni entrar en los detalles del enfoque analítico o la metodología para regionalizar. Lo que quiero aquí es destacar los aspectos de carácter metodológico y epistemológico que el lector enfrenta al principio de la lectura, para poder aclarar lo que para mí representa este texto sobre las regiones de México.

"De México, nos recuerda el autor, se han hecho mil y una delimitaciones regionales [...] la regionalización propuesta en este libro, advierte, es diferente a otras [...] surge de la percepción y la comprensión de la realidad y mezclan la experiencia de quien las vive o ha vivido con la de quien las estudia” (p. 13). Es difícil pensar en alguno, salvo quizá el maestro de muchos geógrafos mexicanos, Ángel Bassols, que como Bernardo haya vivido, recorrido y estudiado el territorio nacional con tanta avidez. Pero contrariamente al maestro Bassols, quien se formó en la escuela soviética de las regiones geoeconómicas, nuestro autor conoce la geografía analítica anglosajona, tanto como la escuela alemana a la que me referiré en un momento. También creo que este libro, 
más que otros del mismo autor, refleja el que Bernardo haya abrevado de la escuela francesa de la geografía, según entiendo de la lectura de un reciente texto de Claude Bataillon de quien, por cierto, fue su mejor alumno en México.

Bernardo García adopta en su libro una visión en la que se mezclan la geografía y la historia, en la que se unen el tiempo y el espacio. Así sucedió paradójicamente en la época en la que geografía e historia eran la misma cosa, y durante el siglo XVIII en el momento de la formación de la geografía como ciencia. De tal suerte que el resultado, más que estrictamente asociado a una escuela en particular, es un excelente ejemplo de geografía cultural.

La geografía cultural -que se ha revitalizado en la actualidadtrata sobre la interrelación de los grupos humanos con su entorno, del impacto, distribución y disposición espacial de culturas y de las diferencias culturales y sus efectos sobre el paisaje. De manera que una región, como apreciamos al leer este interesante, original y necesario texto, se identifica por la presencia de una cultura distintiva, esa suma de rasgos que han conducido a los grupos humanos asentados en un mismo espacio geográfico a darle cierta forma al paisaje, a vivirlo y transformarlo a lo largo de su historia.

Como se percibe en la amena y sistemática descripción que hace Bernardo, la región es resultado de la combinación de múltiples factores que cambian en el tiempo como la inmigración, la introducción de tecnología, los cambios políticos, económicos y sociales producidos ya sea de manera endógena o bien, en su mayoría, exógenamente. Desde luego que un aspecto enfatizado a lo largo de la descripción de las regiones, desde la perspectiva de este historiador, tiene que ver con el proceso de modernización que permea los cambios que con mayor o menor intensidad tienen algunas regiones.

Los geógrafos franceses hablaban de la humanización del espacio, pero quizá habría que pensar en la transformación del paisaje por la acción humana. También de interacción cultural entre grupos diversos que conviven, se enfrentan, invaden pacífica o violentamente un territorio. Ahora sabemos, sin embargo, que por razones de cambio climático el medio natural ejerce enorme presión sobre el paisaje transformado. En ocasiones Bernardo insiste en los rasgos naturales de la región sobre otros atributos. Sin embargo, mantiene el balance con los procesos humanos y no deja que la biología o las ciencias de la Tierra dominen en su descripción de la región. Son sin duda las humanidades y las cien- 
cias sociales las que imprimen el sello de este breviario geográfico e histórico de las regiones de México. Todo se complementa con el recorrido, que representa la forma ortodoxa en la que los geógrafos abordan y presentan su tarea: la parte empírica -el recorrido del sitio- y la parte interpretativa -la historia o el conocimiento de los procesos a lo largo del tiempo-, que tan diestra y nítidamente realiza el autor con y para el lector de su libro.

No puedo dejar de citar la clásica definición de Carl Sauer (1925), en la que se destaca la territorialidad como el elemento explicativo del landschaft o paisaje:

El paisaje cultural resulta de la presencia de un grupo cultural en un paisaje natural. La cultura es el agente y el área natural el medio a partir de lo cual el paisaje cultural se forma. Bajo la influencia de una determinada cultura, que es cambiante en el tiempo, el paisaje sufre un desarrollo que transita por diversas fases y probablemente alcanza un punto final en ese ciclo de desarrollo. Con la introducción de diferentes culturas externas, el paisaje cultural se rejuvenece y un nuevo paisaje emerge sobre lo que queda del anterior (p. 138).

Al igual que Sauer -intuyo que Bernardo se ha inspirado en él-, el autor de nuestro libro se aleja a todas luces el determinismo ambiental o ecológico que en ocasiones ha influenciado a los geógrafos nutridos de las ideas de Ratzel, ese importante geógrafo de la escuela alemana de la geografía. Y al igual que Meinig, aquel geógrafo cultural de gran estatura, en el texto de Bernardo -aunque tratado de modo diferente- aparece el concepto de espacio de transición. Meinig, inspirado en la noción de provincia cultural de Ratzel, identifica el corazón o el área núcleo como aquel espacio geográfico en el que la cultura en cuestión predomina de manera exclusiva, o casi; el dominio en el que se identifican clara, aunque no exclusivamente, los rasgos culturales y, por fin, la región exterior o periférica en la que la cultura, si se encuentra, esta subordinada a otras culturas. El enfoque organicista de Ratzel y el determinismo ambiental o ecologista no puede descartarse plenamente o de tajo de Meinig.

En el texto de Bernardo no hay trazos de dicho enfoque. Más bien su espacio de transición se orienta a explicar lo difícil de las delimitaciones y, más aún, de aquellos espacios en los que aún no se establece un paisaje cultural definido. Tampoco puede eliminarse el enfoque sistemático en la descripción y síntesis regional. En el libro que nos ocupa, esta descripción sistemática nunca es mecánica. Como ejemplo quisiera referir al lector al tratamiento 
que se da a la zona serrana del norte de Puebla (pp. 97-99), que abarca parte de la región que se presenta en el mapa 9.

A lo largo del texto, el lector interesado podrá enriquecer no sólo su conocimiento del territorio nacional y sus regiones, sino también su destreza metodológica. Bernardo nos advierte de las dificultades metodológicas que implica el manejo de datos basados en divisiones político-administrativas, frente a los atributos o procesos naturales o bien socioculturales. Problemas de cercanía y radio de influencia transregionales que por accesibilidad o dependencia funcional permiten desarrollar relaciones estrechas entre asentamientos que de hecho pertenecen a distintas regiones, como es el caso de pequeñas localidades de Jalisco con Zacatecas y otras de este estado con Guadalajara (p. 81). Y en ocasiones la coincidencia de los límites político-administrativos, demográficos y económicos (p. 81).

Narra cómo una región se construye apoyada en un medio físico pero no sujeta a su conformación o sus características ( $p$. 73). Aborda los procesos de diversificación regional a partir de la accesibilidad, como es el caso del Bajío y las localidades de ese "sistema de centros urbanos, el más complejo y equilibrado del país” (p. 71).

Al mismo tiempo vemos que, por un lado, la vecindad no necesariamente condiciona una delimitación regional y, por otro, que no impide el trazo de un lindero que define una región de otra.

Encontramos la definición de región sujeta a circunstancias históricas (p. 106), que no a características del medio físico (p. 111).

Y, además, gozamos de comentarios irónicos y perspicaces, como los que se refieren a las acciones y planes gubernamentales en el caso de la desecación y eliminación del carácter fluvial de la región del Papaloapan por la Comisión del mismo nombre, a partir de 1947: "Basta visitar el pequeño poblado llamado Ciudad Alemán (i!), inmediato a Tuxtepec, para encontrar el símbolo de muchos de los grandes proyectos nacionales: infraestructura de calles bien trazadas, pero vacías y abandonadas entre cañaverales. Se le imaginó como la capital de un emporio agrícola e industrial”. ¿Megalomanía?, ¿corrupción?, ¿ignorancia?, ¿desprecio por el conocimiento de los expertos? O el de Tlacotalpan -también sobre el Papaloapan-, del que dice que ha perdido su importancia económica "por obra y gracia de los fabricantes de paraísos" (p. 112).

En fin, la lectura de Las regiones de México de Bernardo García resulta toda una aventura. La que más me apasionó fue la del 
Golfo, aunque también me interesó el Norte (Baja California) y no menos la Cadena Centroamericana, que recorre desde el Istmo hasta El Lacandón para llegar a Frontera Corozal, donde termina el texto.

El lector no puede dejar de leer con cuidado la introducción. Ahí se aclara lo que es y no es el libro, pero también se hace referencia a este proceso histórico característico de nuestro país durante el siglo xx: el centralismo y la preeminencia económica y política de la capital, del México central. Me hubiera gustado quizá un último capítulo de reflexiones o síntesis que, si bien aparecen en la introducción y a lo largo del texto, habría exigido del autor una mirada por encima de los recorridos a los que nos transporta. Termino recomendando al lector dejarse llevar confiadamente y hacer el recorrido por las regiones de México de la mano de este historiador que más que eso, para mí es todo un geógrafo.

Recibida: 24 de enero de 2009. Aceptada: 16 de febrero de 2009.

Boris GraizBord El Colegio de México graizbord@lead.colmex.mx

Boris Graizbord. Es investigador nacional (SIN III). Desde 1995 coordina el Programa de Estudios Avanzados en Desarrollo Sustentable y Medio Ambiente (LEAD-México) de El Colegio de México. Fue coordinador académico del Programa de Desarrollo Urbano de El Colegio de México en dos ocasiones (1984-1986 y 1994-1995). En 1979 se incorporó a dicha institución como profesor-investigador del ahora Centro de Estudios Demográficos, Urbanos y Ambientales. Desde 1977 es profesor de asignatura en la maestría de urbanismo de la Facultad de Arquitectura de la Universidad Nacional Autónoma de México, y ofrece cursos en la maestría de estudios regionales del Instituto de Investigaciones Dr. José María Luis Mora desde 1992. Ha sido invitado regularmente a impartir cursos completos o cortos en otras instituciones académicas tanto del país como del extranjero (entre otras la University of Southern California, la University of Pennsylvania y la New School University). Fue investigador del Instituto de Geografía en la UNAM (1977-1979); director del Centro de Estudios de Desarrollo Social y coordinador del Programa de 
Maestría de Desarrollo Municipal en El Colegio Mexiquense (1986-1988). Con los auspicios de varias organizaciones y fundaciones, entre ellas el IDRC y el Conacyt, ha coordinado investigación en población y medio ambiente, contaminación industrial, desarrollo de ciudades medias, política regional, geografía urbana y transporte metropolitano en México.

Ha escrito más de 80 capítulos y artículos que han aparecido en libros y revistas periódicas nacionales e internacionales, así como en periódicos y revistas de difusión. El doctor Graizbord ha publicado en colaboración varios libros; el último (2008) de su autoría sobre transporte metropolitano se publicó con el sello de El Colegio de México. Es arquitecto por la UNAM, obtuvo la maestría en geografía urbana en la Universidad de Durham, en el Reino Unido, en 1974 y entre 1974 y 1977 realizó estudios de doctorado en geografía social en la London School of Economics and Political Science. 